\title{
CLIMA E TELEDETECÇÃO: UMA ABORDAGEM GEOGRÁFICA
}

\author{
Vincent Dubreuil ${ }^{1}$
}

\begin{abstract}
RESUMO
A utilização dos dados fornecidos pelos satélites meteorológicos renovou completamente os nossos conhecimentos e a nossa compreensão do sistema Terra-Atmosfera. Graças à repetitividade de observação, a cobertura global do planeta que os satélites nos oferecem, eles tornaram-se instrumentos indispensáveis para os geógrafos climatólogos. No entanto, os dados de satélites não dispensam observações in-situ, as informações adquiridas diretamente comparáveis e a calibração, e a validação dos dados continuam a ser indispensável. Este artigo mostra toda a importância da teledetecção em climatologia a partir de exemplos tomados na França do Oeste (estimativa das temperaturas e acompanhamento da seca à escala regional) e no Brasil (monitoramento das frentes da brisa do mar no Nordeste e estimativa das precipitações no Mato Grosso).
\end{abstract}

Palavras chave: sensoriamento remoto, climatologia, geografia, França, Brasil.

\section{CLIMATE AND TELEDETECTION: A GEOGRAPHIC APPROACH}

\begin{abstract}
The use of the data provided by the meteorological satellites completely renewed our knowledge and our comprehension of the atmospheric system. Thanks to their repetitivity of observation, with the total cover of planet that they offer to us, the satellites became essential tools for the climatologists. For as much, the satellite data do not exempt acquired observations in-situ, information not being always directly comparable and the calibration/validation of the data remaining essential. This article shows all the interest of the teledetection in climatology starting from examples taken in the Western part of France (estimate of the temperatures and drought monitoring at a regional scale) and in Brazil (monitoring of sea breeze fronts in Nordeste and rainfall estimations in Mato Grosso).
\end{abstract}

Keywords: remote sensing, climatology, geography, France, Brazil.

1 COSTEL-LETG UMR 6554 CNRS, Universidade Rennes 2, França, Vincent.dubreuil@uhb.fr. 


\section{Introdução}

Os estudos de climatologia fundamentam-se sobretudo sobre as observações do tempo feitas em diversas estações. Estas observações são às vezes muito antigas, como na China (séries de medidas de chuvas desde a Idade Média) ou mesmo na Inglaterra (XVIIIe). O historiador E. Leroy Ladurie (1983) na sua tese "História do clima desde o ano Mil" provou a utilidade de documentos escritos ou iconográficos para o estudo dos climas do passado. Acontecimentos climáticos puderam também influenciar fortemente o curso da História no momento de certas batalhas (Peguy, 1989). Mas, o conhecimento do clima do nosso planeta não é não somente um desafio estratégico. Fundamentalmente, em primeiro lugar as atividades de subsistência (a agricultura) que dependem do clima. Com efeito, o clima pode aparecer como um recurso e/ou como um constrangimento. O clima não é, por conseguinte, um elemento neutro no espaço ou para o raciocínio geográfico: é um dos elementos que condiciona a ocupação da Terra pelos homens. As adaptações de estes são múltiplas, função do nível de desenvolvimento e dos meios financeiros. Desde os anos 70, a observação por satélite da atmosfera terrestre transformou radicalmente e melhorou o nosso conhecimento dos mecanismos climáticos. Muito cedo, os geógrafos climatólogos compreenderam o interesse dos dados de satélites para os seus estudos: testemunham os artigos precursores de Tonnerre-Guérin (1976), Mounier e Pagney (1982), o sucesso do manual de Barrett (1974), a organização do terceiro colóquio da Associação Internacional de Climatologia (Mounier, 1990) bem como numerosas teses realizadas na França (Tabeaud, 1989; Dubreuil, 1994; Wahl, 1997...) ou no Brasil (Lombardo, 1989; Mendonça, 1995) onde os dados de teledetecção mostraram todas as potencialidades. Este artigo propõe uma tentativa de balanço destes trinta anos de utilização dos satélites que renovaram profundamente a climatologia (Kergomard, 2004).

\section{As fases do desenvolvimento dos satélites meteorológicos}

\subsection{A insuficiência das fontes ao solo}

Até aos anos 1960-70, os dados básicos utilizados pelos climatólogos são medidas "ao solo". Trata-se de observações realizadas em estações ao solo de acordo com regras precisas impostas mundialmente pela O.M.M. (Organização Meteorológica Mundial cuja sede está em Genebra) na França pela METEO-FRANCE e no Brasil pelo INMET. Estes dados são, por conseguinte, pontuais (locais) e devem ser manipular com precaução em longo prazo. E preciso lembrar que para serem comparáveis estas observações devem estandardizar-se (é pelo menos o caso geralmente num dado país), por exemplo, medidas sob abrigo à altura fixa para a temperatura. A qualidade das informações disponíveis pode ser muito variável em função do tipo de material utilizado e a densidade da rede de medidas, muito heterogênea qualquer que seja a escala considerada.

Os dados climatológicos colocam alguns problemas quanto à sua utilização. É necessário, em primeiro lugar, sublinhar a qualidade muito desigual das observações: erros de leituras, defeito dos aparelhos não são detalhes a negligenciar quando se-estuda séries de números. Pode-se, por 
métodos estatísticos simples, detectar erros e às vezes corrigí-los. Os instrumentos de medidas revelam-se, às vezes, inadaptados às condições atmosféricas violentas: pluviômetros debordam quando das chuvas muito fortes (à Nîmes no momento da trovoada de 1988), os anemômetros são levados pelas rabanadas dos ciclones ou das tempestades, como na Bretanha em 1987, de modo que as condições "extremas" não podem ser sempre convenientemente apreciadas.

Além destas observações "de bom senso", derivações mais sutis foram constatadas, vinculados às mudanças de aparelhos ou dos sítios de medidas. As mudanças de aparelhos (ou da hora da medida) afetam a continuidade das séries observadas: pode-se notar diferenças substanciais entre as temperaturas medidas em função dos abrigo de madeiras e dos abrigo de plástico. A mudança de instrumentos de medidas da insolação na França em 1989-1990 provocou uma ruptura nas séries. Sabe-se também que pluviômetros automáticos subestimam as chuvas. Seria necessário, igualmente, considerar as mudanças no ambiente do sítio onde são efetuadas as medidas: a elevação das temperaturas constatada desde várias décadas tem liga-se ao fato de serem realizadas ao interior ou proximidade das cidades. Observou-se mesmo diminuições espetaculares de chuvas ou temperaturas em estações onde uma árvore vizinha tivesse crescido demasiadamente ou onde uma nova construção tivesse sido feita... Isto leva a não se ter ilusões sobre números precisos. Uma grande prudência e muito rigor impõem-se para o estudo das longas séries de medidas. Melhor satisfazer-se com o uso de médias durante trinta anos (normal climática) de estações "confiáveis" geridas por profissionais, o que induz ao questionamento da densidade da rede de medidas.

Lembre-se que na História da meteorologia a primeira rede internacional de medida "foi criada por Ferdinand II, grande duque da Toscana, que lançou uma rede de dez estações de medida que vão de Florença e Pisa a Paris e Varsóvia. A rede funcionou de 1654 a 1667; e sua extinção deve-se à hostilidade da igreja católica frente às empresas científicas " (Rochas \& Javelle, 1993). Na França, a observação meteorológica moderna data da segunda metade do século XIX. Em 14 de Novembro de 1854, em plena guerra da Criméia, uma tempestade violenta lança sobre as costas do Mar Negro numerosos navios da frota franco-inglesa... Este desastre militar poderia ter sido evitado? Para sabê-lo, o Imperador Napoléon III pede uma avaliação ao Urbain Le Verrier, cientista unanimemente reconhecido. Le Verrier rapidamente mostra que a mesma tempestade tinha ocorrido 3 dias antes na França e em seguida em toda a Europa... O acontecimento era, por conseguinte, previsível. Algumas semanas depois, em 19 de Fevereiro de 1855, Le Verrier apresenta à Academia das ciências um "mapa do tempo" que mostra a situação na Europa naquela mesma manhã. Ele aproveita da situação de guerra e da recente instalação do telégrafo elétrico que permite fazer circular rapidamente a informação para lugares muito afastados. Data desta época a criação, na França, de um "serviço de advertência das tempestades", antepassado "da Meteo-France". Em outros lugares na Europa, numerosas criações de comissões meteorológicas resultarão de episódios da primeira guerra mundial, sendo frequentemente a antecipação das condições meteorológicas um dos elementos de sucesso ou malogro de de uma campanha. Isto continua sendo verdadeiro como visto na Guerra do Golfo em 1991: o bom desenrolar das operações militares (incluidos aviões furtivos) depende fortemente das condições meteorológicas e climatológicas. Em alguns paises, o acesso a estes dados 
continua a ser difícil (segredo de defesa!). De certa maneira, a previsão meteorológica aparece frequentemente como o fruto da guerra (Péguy, 1989) um pouco como a "geografia que serve para fazer a guerra"!

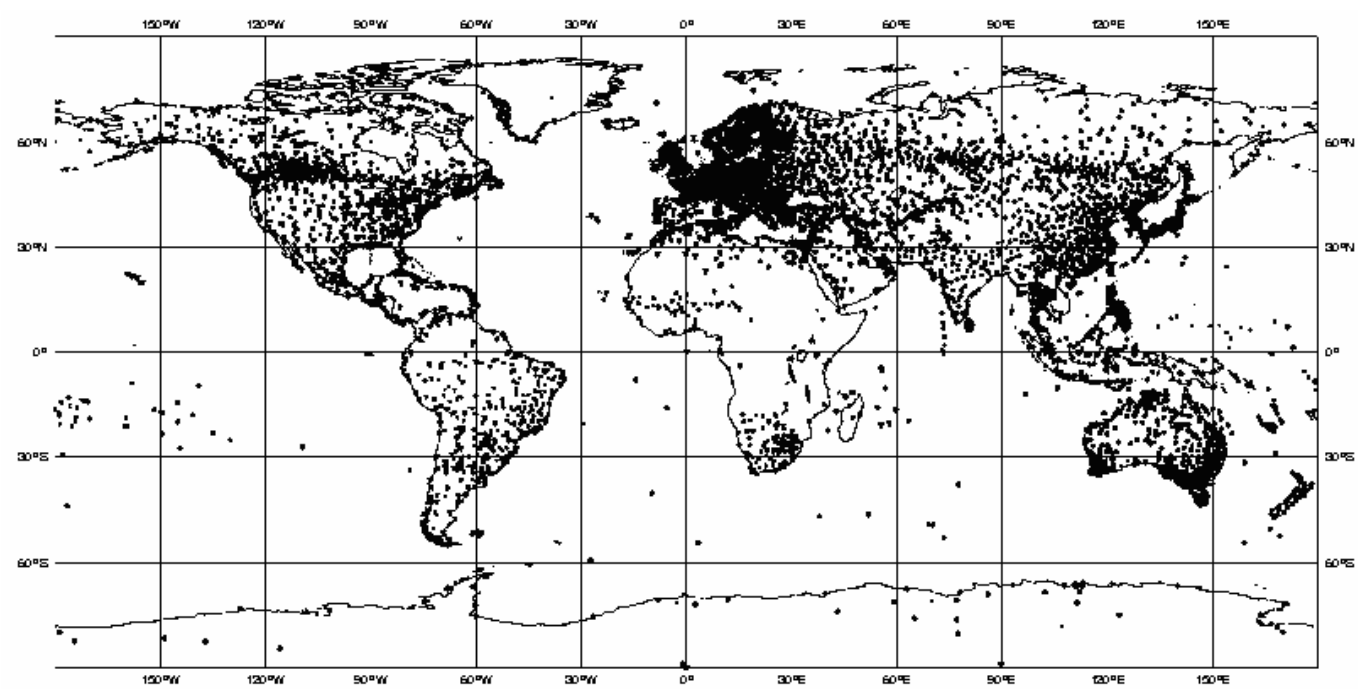

(A) A rede de observação meteorológica mundial.

Fonte: OMM, http://www.wmo.ch/index-en.htm/
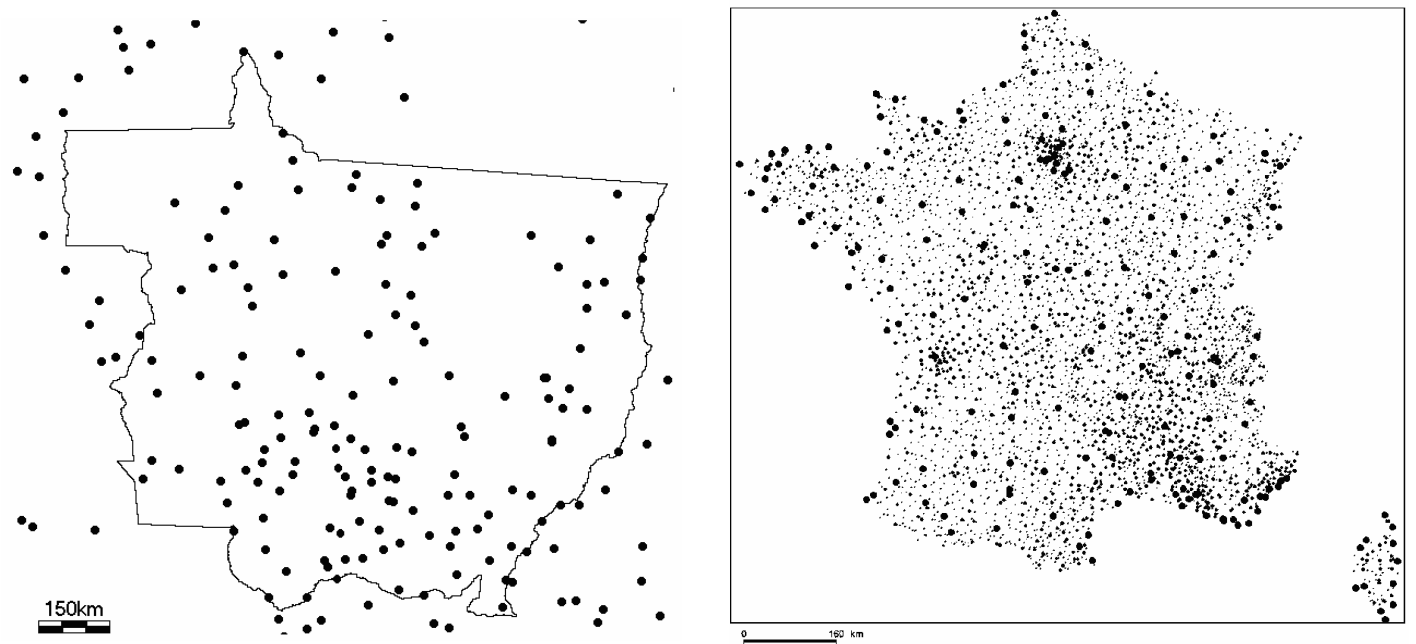

(B) As redes de estações pluviométricas do Mato Grosso (Fonte: V.Dubreuil et al., 2004) e da França (Fonte: Meteo-France http://climatheque.meteo.fr/aide/climatheque/reseauPostes/) na mesma escala.

Figura 1. As redes de observações meteorológicas no solo

O mapa da rede mundial das 20.000 estações oficialmente reconhecidas pelo O.M.M. é rico de ensinamentos (figura 1A). Mostra, primeiro, a concentração maior nas terras em relação aos oceanos (no entanto mais de $70 \%$ da superfície do globo) estes ainda mal conhecidos apesar de uma rede de 450 bóias de deriva e as medidas efetuadas à bordo de 7000 navios. Nota-se, além disso, uma excessiva concentração no hemisfério norte e sobretudo nas 
médias latitudes: a observação meteorológica pode, por conseguinte, parecer um luxo, um privilégio dos países ricos! Este mapa permite reencontrar igualmente as regiões de fracas densidades humanas (ver a Sibéria e as estações ao longo da transiberiana). Força a constatar que a informação meteorológica é descontínua. Para certas informações como as fornecida pelas radiosondagens a situação é bem pior com pouquíssimos pontos (menos de 500 para todo o globo), a mesma quantidade sobre a Alemanha que para toda a África, mais sobre os EUA que para o conjunto dos oceanos... Ilustraremos agora este problema da densidade da rede de informação pluviométrica (figura 1B) a partir das redes do Mato Grosso (907000 km²) e da França (551000 $\left.\mathrm{km}^{2}\right)$.

O conhecimento climatológico da parte meridional da Amazônia brasileira e sobretudo do Mato Grosso evidencia grande lacuna (Nimer, 1989). Os postos de medidas são pouco numerosos, frequentemente pouco mantidos e foram instalados somente depois dos anos 1970, no início da colonização agrícola (Dubreuil et al., 2004). Na região de mais de um milhão de quilômetros quadrados existem cerca de 200 postos cujas medidas de precipitações estão disponíveis: essencialmente as estações do INMET (Instituto Nacional de Meteorologia brasileiro) e da ANA (Agência Nacional da Água). Isto representa apenas um ponto de medida para cerca de $15000 \mathrm{~km}^{2}$, continua potanto a ser insuficiente para um estudo à escala regional. O mapa da figura 1B mostra também a desigual densidade da rede com vazios problemáticos no sudoeste de Rondônia, no Sul do Pará ou no sudeste boliviano. Além disso, a maior parte destas estações é de criação recente, a metade delas em serviço ha menos de 20 anos. Tal diagnóstico permite compreender a ignorância desta região no plano climatológico.

Na França, a rede da Metéo-France (cujo centro é situado em Toulouse) apoia-se sobre a trama departamental: CDM (para Centro Departamental da Meteorologia). No total, são pouco mais de 3000 pontos de medidas (um para $180 \mathrm{~km}^{2}$ ) de qualidade heterogênea que se-espalham pelo território. Numerosas lacunas espaciais existem, especialmente nas montanhas (elevadas altitudes ou ubacs). Para preencher as lacunas espaciais, qualquer que seja a região estudada, uma possibilidade de interpolação espacial à malha regular pode ser fornecida pelos satélites. Além disso, contrariamente aos dados de solo, frequentemente díspares, a informação dos satélites é coerente e homogênea. Por último, a repetitividade das suas observações é bem superior à dos postos de medidas que dependem de benevolos. Compreende-se melhor porque, muito cedo, as técnicas de observação satélite em meteorologia tomaram um carácter operacional.

\subsection{Um desenvolvimento progressivo de técnicas agora operacionais}

A importância dos satélites em climatologia e meteorologia excede o quadro da pesquisa em geral. A sua utilidade não precisa mais ser demonstrada para numerosas atividades econômicas (agricultura, pesca...). 0 acompanhamento e a previsão das condições meteorológicas (causa de $20 \%$ dos acidentes da estrada na França) condiciona a nossa vida diária e as imagens dos satélites meteorológicos são amplamente difundidas ao público (não ha boletim meteorológico na televisão sem animação de satélite!). Mais ainda que as outras imagens de satélites, aquelas fornecidas pelos satélites 
meteorológicos são produtos cotidianos (Bader et Al, 1995).

Desde o início da teledetecção por satélite uma prioridade foi a observação do espaço da atmosfera terrestre. Dos anos 1960 até o final dos anos 1980, o essencial dos satélites foi de tipo militar: mais de $80 \%$ de cerca de cinquenta lançamentos anuais são satélites de observação estratégica e apenas 2 a 4 para a observação civil (especialmente os programas Landsat e Spot). Mas, durante estas três décadas, os lançamentos de satélites meteorológicos ja eram em média 5 à 6 por ano. Depois de 1991 e com o fim dos regimes soviéticos e comunistas da Europa do Leste, os satélites meteorológicos e de observação civis são mais numerosos que os satélites militares mas em 2 vezes menor o número de lançamentos e maior diversidade de países lançadores: os países "pioneiros" (EUA, Rússia) assim sofrem concorrência da Europa, do Japão seguidos por países emergentes como a China, o Brasil, a Índia ou Israel, que se dotam igualmente de programas espaciais. O releitura destes quarenta e cinco anos de observação satélite do nosso planeta permite distinguir quatro fases sucessivas de cerca de dez anos cada uma.

O início da teledetecção meteorológica ocorre após a segunda guerra mundial: em 1947, os Estados Unidos transformam foguetes V2 em lançadores equipados de aparelhos de medidas e câmaras ópticas. As primeiras fotografias de sistemas nebulosos do espaço (vista de 110-165 Km de altitude) datam desta época. Embora não se possa ainda falar de satélite, estas observações revelam a complexidade dos sistemas nebulosos (à era da frontologia norueguês) e o interesse de uma visão global destes sistemas. A era da teledetecção meteorológica com satélite começa realmente após o Spoutnik (Outubro de 1957) e a criação da NASA (National Aeronautics and Space Admninistration) em Março de 1958 que lança o primeiro satélite meteorológico para a estimativa do balanço da energia terrestre: "First Earth Radiation Experiment". Mas, a data mais importante é o 1 Abril de 1960 com o lançamento de TIROS-1 (Television and InfraRed Operating System), primeiro satélite verdadeiramente meteorológico que demonstra a complexidade e o interesse da abordagem satélite (de certa maneira, coloca mais problemas aos meteorologistas do que responde às suas questões), e a necessidade de uma abordagem global e de uma cooperação internacional para a vigilância global da atmosfera terrestre. Resulta assim a instalação, por meio da Resolução da O.N.U de Dezembro de 1962, o World Weather Watch sob a egide da OMM e o «Global Atmospheric Research Programm » (GARP). A primeira geração dos satélites de órbita polar TIROS (10 aparelhos do mesmo tipo até 1965 sobre órbitas inclinadas de 48 à $58^{\circ}$ em relação ao Equador que cobrem somente as baixas e médias latitudes) seguida pelo ESSA (Environmental Science Services Administration) é dos anos 1960. Os 9 aparelhos ESSA (lançados de 1966 até 1969) têm órbitas quase-polares e observam tambem os pólos. Mostram a viabilidade operacional dos captores e os sistemas de transmissão APT (Automatic Picture Transmission) e « stockage on board » (dados recuperados pelas estações no solo da Virginia e do Alasca). Do lado russo, o primeiro satélite meteorológico, COSMOS-122, é lançado em 1966 e METEOR-1, em 1969, é o primeiro satélite operacional munido de um sistema de observação TV.

A década 1970 é a do desenvolvimento e a consolidação dos sistemas de observações meteorológicos. Apesar das dificuldades econômicas, 
o prestígio da NASA com as missões Appolo permitiu desenvolver novos programas mais operacionais. É necessário sublinhar, primeiro, o desenvolvimento das plataformas geoestacionárias no meio da década: lançamento de GOES-1 em 1974 seguido do METEOSAT-1 e GMS-1 em 1977. Do lado dos satélites de órbita polar, uma segunda geração aparece com ITOS (Improved Tiros Operational System) lançado em Janeiro de $1970 \mathrm{com}$ duplo sistema de transmissão (APT + stockage) e das resoluções espaciais de 1 para $4 \mathrm{Km}$ no visível e no infravermelho; o $\mathrm{n}^{\circ} 2$ (Dezembro de 1970) é rebatizado NOAA-1, a NOAA (National Oceanic and Atmospheric Administration), sucessor do ESSA, integrou-se no "US department of commerce" mostrando a entrada das imagens dos satélites meteorológicos no domínio operacional e... comercial. Esta primeira série de satélite NOAA é equipada do radiômetro VHRR (Very High Resolution Radiometer) e de uma sonda vertical de temperatura. Em 1975, a segunda geração dos METEOR russos embarca igualmente um radiômetro. Destaca-se que nessa época são postos em órbita os primeiros satélites de observação da terra à elevada resolução (LANDSAT MSS em 1972 antes de Spot em 1984).

Um momento decisivo importante opera-se em 1978 com a chegada de uma nova geração dos NOAA: o radiômetro AVHRR (Advanced Very High Resolution Radiometer) sobre TIROS-N lançado em 1978, observa a superfície terrestre em 4 bandas espectrais: $0.55-0.90 \mu \mathrm{m}, 0.73-1.1 \mu \mathrm{m}, 3.5-3.9 \mu \mathrm{m}$ et 10.5-11.5 $\mu \mathrm{m}$. A partir de NOAA-6, a banda do canal 1 foi reduzida para melhor discriminar a cobertura da neve $(0.55-0.7 \mu \mathrm{m}$ para $0.58-0.68 \mu \mathrm{m})$ : assim pôde igualmente ser calculada a partir de 1980 dos índices de vegetação que combinam as informações do canal 1 e do canal 2, infravermelho proximo (Dubreuil et al., 2002). Por último, a partir de NOAA-7, um quinto canal foi acrescentado $(11.5-12.5 \mu \mathrm{m})$ para fornecer melhores estimativas das temperaturas de superfície do mar (Tucker, 1996). Esta configuração de 5 canais que equipam o radiômetro AVHRR está instalada no NOAA-17 lançado em 2002. O ano 1978 é quando é lançado uma série de plataformas experimentais como SEASAT e NIMBUS. Na década que se-segue os programas operacionais são instalados de maneira perene e uma certa "rotina" instala-se, para a maior parte. Em paralelo, grandes esforços são realizados para a integração dos dados de satélites nos modelos de previsão meteorológica : em Agosto de 1979 ao ECWMF (European Center for Medium-range Weather Forecasts) de Reading é realizada a primeira utilização diária de um modelo global e a integração dos dados de vento procedentes do geoestacionários (Pailleux, 2002). De uma certa maneira, o esforço leva ao desenvolvimento dos modelos e parece deixar em segundo plano a tecnologia espacial meteorológica. Além disso, a nova perspectiva científica centrada no "global-change", no início, dispensa o contributo da teledetecção.

Assim, os anos 1990 aparecem marcados ao mesmo tempo por uma série de dificuldades e pela chegada de uma nova geração de captores. As dificuldades dos programas de satélites são de naturezas diversas: explosão do lançador espacial Challenger na decolagem em 1993, dificuldades de desenvolvimento da série Goes-next (sistema de estabilização dos 3 eixos), malogro da missão LANDSAT 6, perda de NOAA-13 em 1993 depois de 13 dias... Mas, ao mesmo tempo, novos sistemas de observação são instaurados: radares e altímetros (TOPEX Poseidon, ERS...), instrumentos dedicados à observação dos oceanos e das interações oceano/atmosfera (POLDER, AQUA,...), instrumentos de sondagem atmosférica mais eficientes (ATOVS sobre 
NOAA-15). As resoluções espaciais (a partir de agora métricas) e espectrais (várias dezenas de canais) refinam-se. A evolução refere-se igualmente a observação geoestacionária com a nova série dos GOES americanos (1994) e com a chegada de Météosat Segundo Geração (MSG). No plano temático, é necessário assinalar o reenquadramento que se operam igualmente durante este período. Com efeito, as séries de dados de satélites começam a ser mais exploráveis para a climatologia porque as observações duram desde o final dos anos 1970, cerca de 20 anos de observação para os produtos NOAA ou GOES. Observa-se igualmente uma importância crescente dos dados de satélites para abordagens globais da atmosfera, oceanos, da biosfera (continental e marinho), da cobertura de neve e gelo, etc... (Gurney et al., 1993). Ao final, a tecnologia meteorológica espacial permitiu em quarenta anos uma profunda renovação das abordagens e dos métodos de trabalho dos climatológos e dos geógrafos e ainda mais uma grande quantidade de dados procedentes de uma variedade de captores é acessível para a comunidade científica.

\subsection{Os diferentes tipos de satélites meteorológicos}

Convém lembrar primeiro que estas ondas classificam-se em função do seu comprimento de onda no vazio: no espectro electromagnético, o olho humano percebe apenas uma gama limitada de comprimentos de ondas, a radiação visível (de 0,4 para $0,7 \mu \mathrm{m}$ ). Existe comprimentos de ondas mais curtos (ultravioleta) e mais longos (infravermelho, ondas rádios...) que veiculam certa quantidade de energia. Os detectores dos satélites (radiômetros) são sensíveis à energia veiculada pela radiação que o atinge: uma calibração adequada permite registar valores em certos comprimentos de ondas ou em uma parte do espectro. Isto define um canal ou a resolução espectral do captor. De acordo com a frequência de aquisição dos dados pelo radiômetro do satélite, a distância ao solo que separa duas medidas sucessivas será diferente: fala-se então de resolução espacial elementar do captor e define-se o Pixel (do inglês picture element), o menor elemento que constitui uma imagem de satélite correspondendo à uma medida radiométrica. Por exemplo, o satélite Spot-4 tem uma resolução espacial de 10 metros em modo pancromático, 20 metros em multibanda; LANDSAT-TM tem uma resolução de 30 metros, METEOSAT-3 de 2,5 para $10 \mathrm{Km}$...

Os satélites meteorológicos constituem a parte mais importante dos satélites de observação da Terra (Burroughs, 1991). Distingue-se classicamente os satélites geoestacionários dos satélites de órbita polar: detalharemos a sua utilização na França e no Brasil a seguir. Além dos satélites operacionais geoestacionários e de órbita polar, numerosos programas de satélites meteorológicos foram realizados desde os anos 1960, entre aos programas mais representativos pode-se mencionar os satélites NIMBUS (monitoramento do ozônio e desenvolvimento de captores), TOPEX-POSEIDON (radar altimétrico), DMSP (satélites militares com um captor microondas para as precipitações), TRMM (primeiro radar de precipitações embarcado)...

NIMBUS : trata-se de um conjunto de 7 engenhos lançados de 1964 para 1978 que permitiram o desenvolvimento de diversos sistemas de captores, profilores, transmissões: Nimbus-5, em 1972, embarcou o primeiro radiômetro em microondas passivas. Estes satélites foram os primeiros a realizar medidas da emissividade das nuvens, da concentração de gases e de aerossóis, da 
composição da água de mar, do teor de ozônio. NIMBUS-7, lançado em 1978 é um exemplo de longevidade: sua missão que deveria terminar em 1984 prosseguiu-se até 1994 ! A bordo, o instrumento TOMS (Total Ozónio Mapping Spectrometer) com 6 bandas no ultravioleta (de 313 para $380 \mathrm{~nm}$ ) foi decisivo para detectar e monitorar o "buraco na camada de ozônio". Estes aparelhos também permitiram quantificar a cobertura da neve.

O satélite Franco-americano TOPEX-POSEIDON foi lançado por Ariane-4 em 10 de Agosto de 1992: esta missão é uma fusão do programa TOPEX da NASA e o projecto POSEIDON do CNES. A seu bordo, um altímetro francês experimental e um altímetro americano operacional permitiram seguir as deformações da superfície terrestre, a amplitude das ondas sobre os oceanos... A sua órbita à $1336 \mathrm{~km}$ e inclinada de $66^{\circ}$ permitiu uma observação de $90 \%$ dos oceanos mundiais, com sobrevôo de um mesmo ponto a cada 10 dias.

Vinte e cinco satélites DMSP (Defense Meteorological Satellite Programm) foram lançados desde 1966: os seus produtos, por muito tempo, estiveram disponíveis apenas em documentos foto e não numérica porque a sua vocação era fornecer primeiro informações às forças armadas americanas. Trata-se de aparelhos próximos dos NOAA com medidas do visível $(0,4-1,1 \mathrm{um})$ e do infravermelho (10,5-12,5um). Desde 1987, embarcam sobretudo um captor SSM/I (Special Sensor Microwave Imager) que toma medidas em 4 frequências microondas $(19,22,37$ et $85 \mathrm{GHz})$ com uma resolução cerca de 30 $\mathrm{Km}$. Permite, por conseguinte, um acompanhamento do conteúdo de água das nuvens e as precipitações com bons resultados sobre os Trópicos.

TRMM (Tropical Rainfall Measuring Mission) é uma missão americano-japonesa lançada em 27 nov.1997 da base japonesa de Tanegashima. A órbita circular à $350 \mathrm{~km}$ de altitude entre $35^{\circ} \mathrm{N} \& S$ permite seguir de maneira detalhada as regiões tropicais. Em seu bordo, encontram-se vários aparelhos sobretudo:

- o primeiro radar de precipitações embarcado no espaço;

- LIS : Lightning Imaging Sensor, câmara e filtros que recebem unicamente a luz dos relâmpagos (uma primeira quantificação revela que $90 \%$ dos relâmpagos se produzem sobre os continentes).

O interesse dos satélites meteorológicos ficou evidente depois a excelente prevenção realizada no momento da passagem do ciclone Camille (um dos mais potentes do século) sobre o sudeste dos Estados Unidos em 1969: o alerta dado nessa época, após as observações de satélites, sem dúvida, poupou a vida de centenas de pessoas. A vantagem dos satélites provem sobretudo, da frequência de suas observações e o acompanhamento da dinâmica espacial dos fenômenos meteorológicos (perturbações). A partir dos anos 70 passou a ser possível espacializar dados térmicos e as coberturas nebulosas tão importantes para o conhecimento do clima e a previsão meteorológica. Considera-se assim que os satélites permitiram aumentar de 2 dias o período de previsão considerado fiável (5 dias). Entre as numerosas utilizações correntes dos produtos satélites em climatologia pode-se destacar o programa ISCCP (monitoramento da cobertura de nuvens), a estimativa das precipitações a partir dos dados METEOSAT, o acompanhamento da seca e do fenômeno el-nino, etc... 


\section{Exemplos de utilização dos satélites geoestacionários no Brasil}

Os satélites geoestacionários asseguram, desde 1977, uma cobertura quase-global do globo terrestre, somente as elevadas latitudes são excluídas. Um conjunto de cinco satélites efetua um acompanhamento regular da situação meteorológica para todo o planeta. Assim, os satélites METEOSAT, realizados pela Agência Espacial Européia (E.S.A.), observam o fuso EuropaÁfrica, os satélites americanos GOES observam os fusos América-Atlântico e América-Pacífico, os satélites japoneses GMS o fuso Asia- Pacífico -Océania, o fuso Ásia- Oceano Indico observado por missões russas (GOMS), indianas (INSAT) ou chinesas (FY-2). Em todos os casos, trata-se de engenhos geoestacionários, ou seja, que parecem fixos em relação à superfície da Terra, pois deslocam-se ao mesmo tempo que ela à $36.000 \mathrm{Km}$ de altitude. Enquanto a resolução espacial permanece ha muito tempo de aproximadamente 5 à 10 quilômetros e com uma resolução temporal, horária ou semi- horária, os programas geoestacionários conheceram profundas melhorias nos últimos dez anos. Assim, desde 2002, o programa METEOSAT entrou numa nova fase, com o lançamento de MSG (Météosat Segunda Geração). O desempenho aumentou bastante com novas bandas espectrais, com a resolução quilométrica no visível (como para os GOES americanos desde 1994), e com uma frequência de aquisição de imagem a cada 15 minutos.

\section{Comparação dos desempenhos de Météosat e de MSG:}

\begin{tabular}{lll}
\hline & Météosat & MSG \\
\hline Visível & um canal $(5 \mathrm{~km})$ & 4 canais (HRV 1 km) \\
Infravermelho meio & um canal $(10 \mathrm{~km})$ & 3 canais $(3 \mathrm{~km})$ \\
Infravermelho térmico & um canal $(10 \mathrm{~km})$ & 5 canais $(3 \mathrm{~km})$ \\
Repetitividade das imagens & 30 minutos & 15 minutos \\
\hline
\end{tabular}

A elevada frequência de aquisição de imagens permite produzir animações sobre o dia (boletins emitidos por televisão), o mês ou o ano. São elementos chave da previsão meteorológica moderna porque permitem voltar a marcar os movimentos da atmosfera (campo de vento) a partir da observação contínua das formações nebulosas. Os primeiros elementos da nossa atmosfera observados pelos satélites são, com efeito, as nuvens. Em 1983 começou o programa ISCCP (International Satellite Cloud Climatology Program): tratavase de constituir uma base de dados globais para o estudo das nuvens a partir dos dados (visível e infravermelho) de satélites geoestacionários e de órbita polar. As sínteses são realizadas à escala do conjunto do globo a cada 3 horas e resoluções diferentes (de 30 kilometros até $2^{\circ} 5$ ). Sínteses mensais estão igualmente disponíveis. À escala regional e local, vários estudos utilizaram os dados de satélites para realizar acompanhamento da cobertura nebulosa (Mounier \& Lozac'h, 1981). Ilustraremos nosso propósito a partir da cartografia das frentes da brisa do mar no Nordeste antes de estudar a relação entre dados pluviométricos ao solo e o sinal de satélite no Mato Grosso. 


\subsection{Monitoramento das frentes da brisa maritima no Nordeste}

As circulações da brisa do mar favorecem o surgimento de alguns tipos de tempo característicos ao litoral e de uma orla continental de extensão variável. Estes tipos de tempo particulares, relativamente frescos, úmidos e freqüentemente ensolarados em relação às regiões interiores têm inúmeras repercussões sobre as atividades humanas (turismo balneário, poluição atmosférica, etc...). A teledetecção permite colocar em evidência algumas manifestações de nebulosidades características da brisa do mar (frente da brisa), mas que freqüentemente é utilizada como ilustração e mais raramente como meio de cálculo e análise. A chegada da brisa do mar sobre o litoral se traduz habitualmente por uma mudança da direção do vento na superfície (de um simples desvio a uma inversão completa, em função da direção do vento dominante) associado a um aumento de sua velocidade, uma baixa da temperatura, um aumento da umidade relativa e uma mudança do estado do céu. O ar marinho mais denso, estável e fresco eleva o ar continental mais quente e instável, ativando a convecção no nível da frente da brisa e permite a formação de uma linha de nuvens do tipo cumuliforme, paralela à costa e impulsionada para o interior pela brisa do mar. Graças a esta nebulosidade característica sobre o interior do continente, a frente da brisa maritima é freqüentemente detectável sobre as imagens de satélites, enquanto que o litoral e a orla continental se beneficiam de um céu limpo (Damato e al., 2003)

As imagens visíveis GOES-8 (comprimentos de onda compreendidos entre 0.58 e $0.68 \mu \mathrm{m}$ ) foram utilisadas pois os registros efetuados nestes comprimentos de onda permitem discriminar os tipos de nuvens em função de seu albedo: este varia notadamente em função da espessura da nuvem e de sua densidade. As imagens assim obtidas permitem identificar claramente a forma, a extensão e os contornos das nuvens e as formações de nebulosidades, e distinguir as nuvens baixas das superfícies oceânicas e continentais. Para este estudo, os dados foram registrados todos os dias às 18:00 UTC (15:00 locais no nordeste do Brasil) para os meses de setembro a dezembro do ano 2000. O método utilizado consiste em identificar a nebulosidade susceptível de ser ligada as frentes de brisa (linhas de cúmulos paralelos à costa, sobre o continente), ou seja, traçar as frentes observadas sobre os mapas a fim de estimar a freqüência de aparição.

Sobre a orla nordeste do Brasil, a posição das frentes de brisa do mar mostra um gradiente espacial muito fechado. Este limite é materializado pela forte densidade das observações para todos os meses. A topografia acidentada da orla exposta à leste torna difícil a identificação das frentes de brisa do mar, pois estas são freqüentemente mascaradas por outras formações de nuvens ligadas aos efeitos orográficos (figura 2A). Às 18:00 UTC, a penetração é mais importante quando se avança na estação seca: em setembro (figura 3), as frentes de brisa do mar foram observados no interior das terras a uma distância do litoral, compreendida entre 40 e $80 \mathrm{~km}$, com uma freqüência máxima de aproximadamente $60 \mathrm{~km}$ da costa. O maximum de penetração (60 a $100 \mathrm{~km}$ ) parece ser atingido em novembro (figura 3). Nas Guianas e em torno da desembocadura do Amazonas, a distância de penetração é pelo menos de uma centena de quilômetros, mas penetrando para o interior, a nebulosidade ligada a frente de brisa se mistura àquela de maior amplitude (figura 2B), ligada à atividade convectiva acima dos espaços florestais. O traçado quase 
retilíneo da costa do Ceará facilita as observações das frentes da brisa (figura 2C) e permite determinar de que maneira se modula a penetração das frentes em função da orientação da costa. As frentes da brisa melhores assinaladas e desenvolvidas estão associados a um vento sinóptico fraco e de direção oposta à brisa do mar, mas um vento sinóptico fraco e de mesmo sentido que a brisa do mar favorece a penetração da frente para o interior.

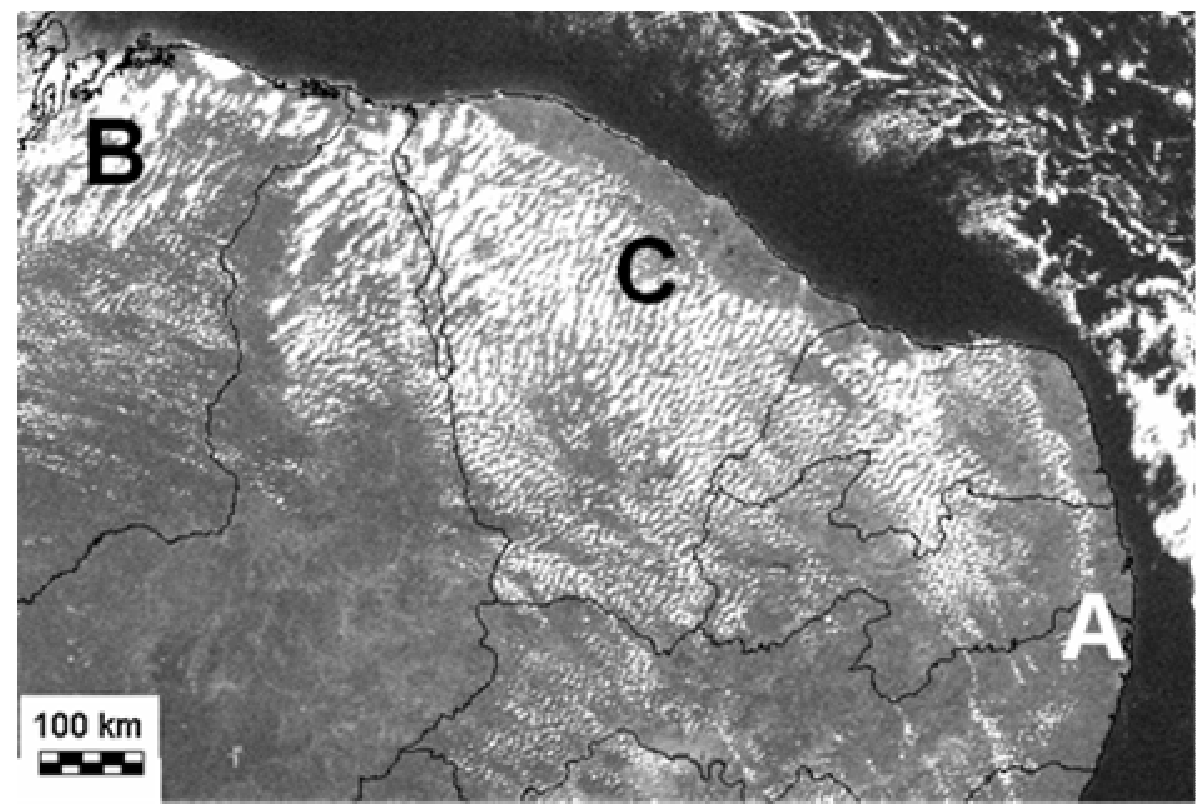

Figura 2. Imagem GOES (visivel) do dia $25 / 6 / 1997$ as 18 h00 UTC mostrando a variedade das frentes da brisa maritima no Nordeste.

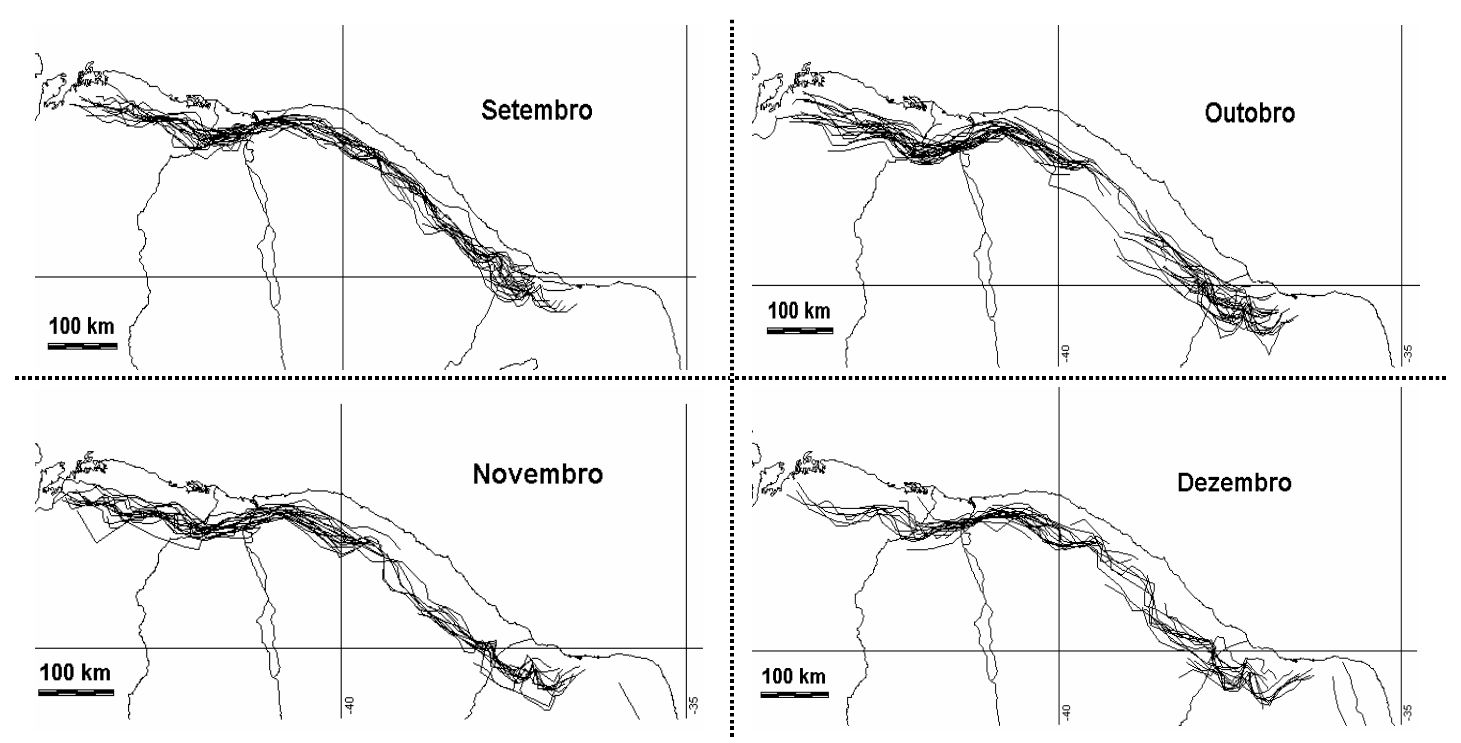

Figura 3. Sínteses mensais das observações das frentes da brisa maritima (2000).

A acentuação do gradiente térmico da superfície terra-mar ao curso 
da estação seca permite evidenciar as condições térmicas favoráveis ao desenvolvimento de possantes circulações de brisas do mar e, portanto, capazes de penetrar mais a dentro no interior; os alísios aportando a umidade atmosférica necessária à formação de nuvens no nível da frente de brisa. E mais, parece que a partir do limite de $4^{\circ} \mathrm{C}$, um desvio de $1^{\circ} \mathrm{C}$ a mais equivale em média a 10 quilômetros suplementares percorrido pela frente da brisa.

\subsection{Estimativa das chuvas no Mato Grosso}

A ausência de uma rede densa de observações meteorológicas de qualidade, característica própria de regiões com pouca densidade de população e com valorização recente, torna necessária a utilização do sensoriamento remoto para que se possa desenvolver um estudo climatológico detalhado. A exploração de dados de satélites para estimar as precipitações não cresceu sem cessar nos últimos vinte anos. Estas experiências deram lugar aos vários programas internacionais de pesquisas (Arkin \& Janowiack, 1993). As técnicas que utilizam o infravermelho térmico foram as primeiras utilizadas. Geralmente são baseadas na relação indireta que existe entre a temperatura do topo das nuvens e a intensidade das precipitações: os algoritmos são baseados no fato de que uma cimeira fria de nuvem traduz a presença de uma nuvem espessa, geralmente a origem de chuvas convectivas na superfície. Estes métodos são particularmente adaptados à zona tropical onde o essencial das chuvas é de natureza convectiva. Este item evidencia como os dados do infravermelho, originários de satélites geoestacionários GOES, podem suprir a baixa densidade da rede de observação clássica no Mato Grosso, bem como apresenta uma cartografia das precipitações em escala regional para o período de setembro 2000 a agosto 2001.

O método utilizado aqui combina dois conjuntos de dados :

- Um primeiro tratamento foi elaborado utilizando um conjunto de dados diários com valor máximo de temperatura observada por cada pixel. As sínteses mensais permitem eliminar os efeitos atmosféricos, afim de conservar apenas a emissão proveniente do solo onde a intensidade é, sobretudo, função da natureza da cobertura vegetal e de sua alimentação em água. Estudar as variações das temperaturas máximas radiativas (TBMax) implica, na verdade, na identificação das quantidades de água da chuva recebidas em um ponto. Este tipo de método foi utilizado principalmente sobre a Àfrica, no âmbito do programa EPSAT, que mostrou uma relação existente entre as TBMAx e as precipitações.

- Um segundo conjunto de dados foi constituído selecionando as mesmas imagens à partir de $-40^{\circ} \mathrm{C}$ : assim, a ocorrência de nuvens de topo frio (do tipo convectivo e com possibilidades de chuvas) pôde ser igualmente monitorada num período mensal. Este método foi adaptado do trabalho precursor de Arkin sobre o Goes Precipitation Index, utilizando-se apenas a temperatura mais baixa $-40^{\circ} \mathrm{C}$ ao invés de $-38^{\circ} \mathrm{C}$, após os resultados obtidos por Cadet et Guillot (1991). 


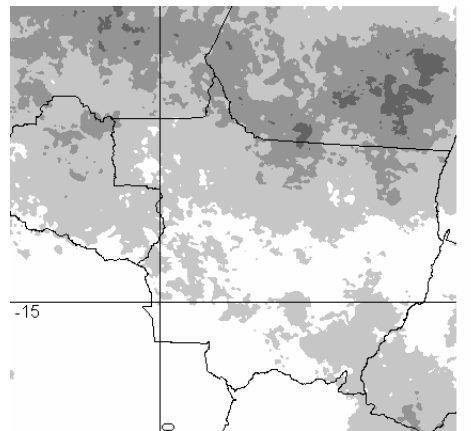

Setembro 2000

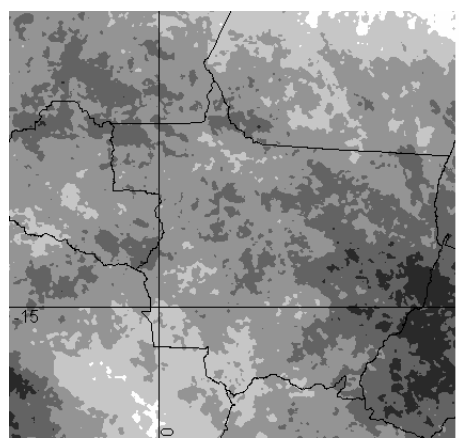

Dezembro 2000

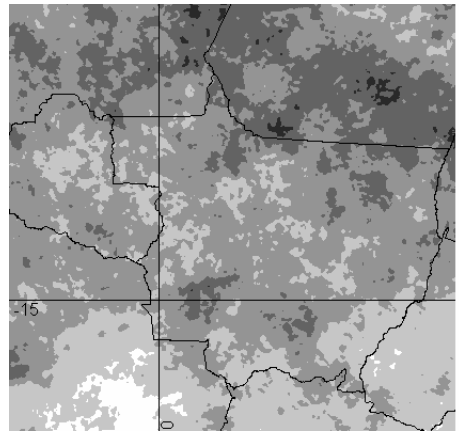

Dezembro 2000

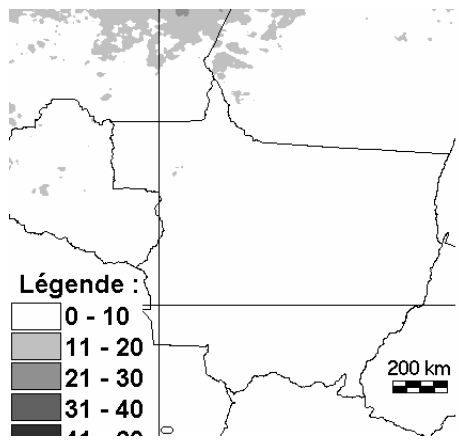

Março 2000

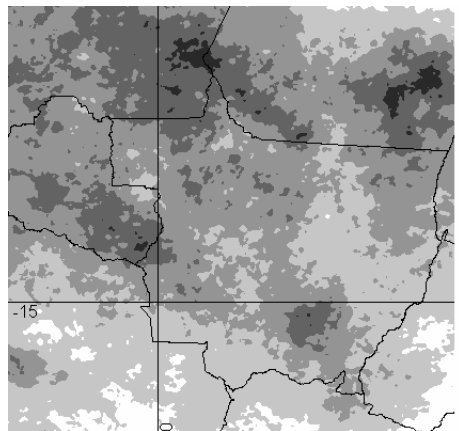

Outubro 2000

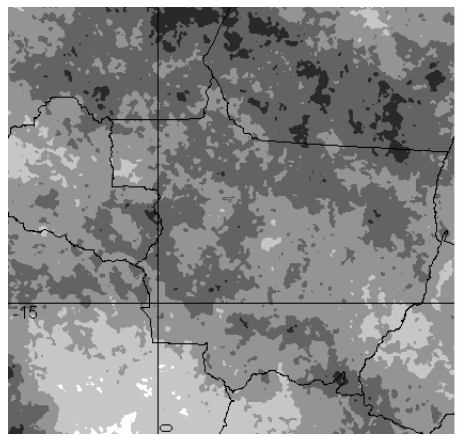

Janeiro 2000

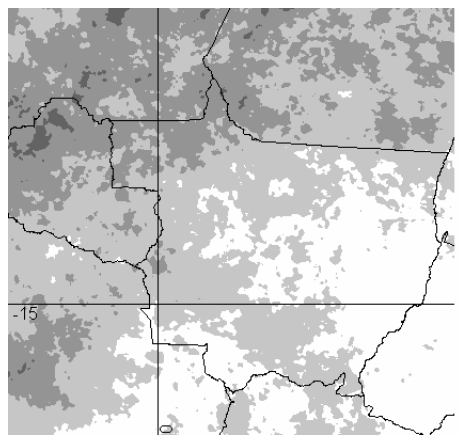

Janeiro 2000

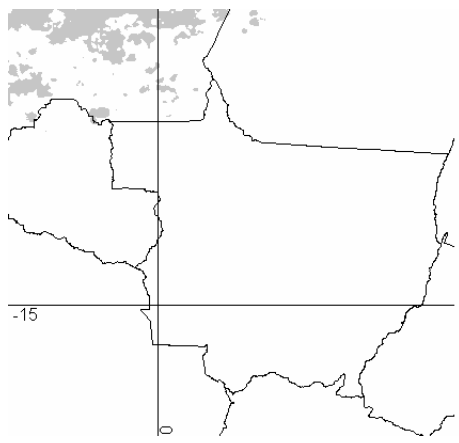

Abril 2000

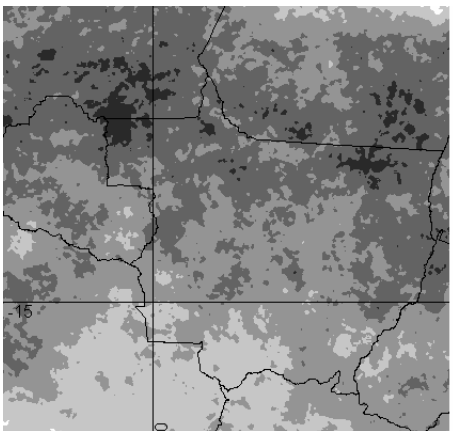

Novembro 2000

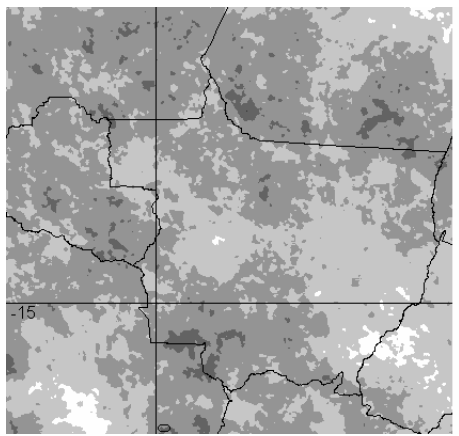

Fevereiro 2000

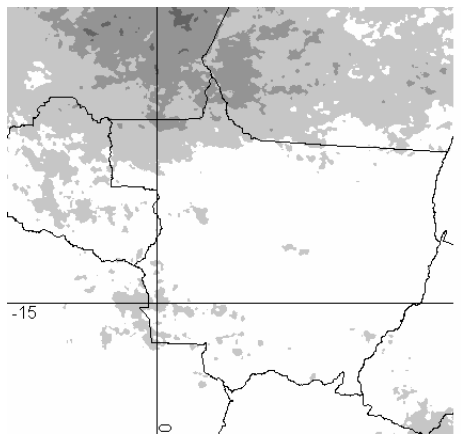

Fevereiro 2000

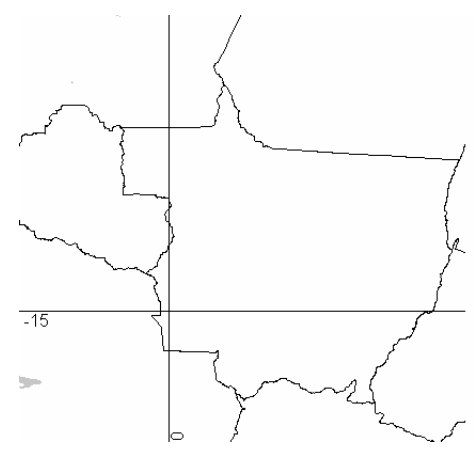

Maio 2000

Figura 4. Ocorrências de nuvens de topo frio (GOES) no Mato Grosso : 2000-2001.

As imagens da figura 4 permitem acompanhar o desenvolvimento da ocorrência de nuvens de topo frio em relação àquelas das precipitações na 
região de Mato Grosso. Os coeficientes de correlação mensais (Tabela 1) calculados para cada mês evidenciam, claramente, que existe um vínculo entre os dados de satélites e as precipitações registradas em superfície. Mas, embora exista certa coerência nos resultados da correlação, os vínculos entre as precipitações e os dados de satélite não são sempre muito fortes: as correlações com as ocorrências são melhores tanto no início quanto no fim da estação chuvosa, bem como com as TBMax no meio da estação das chuvas. De uma forma geral, as precipitações são melhores correlacionadas durante a ocorrência de nuvens de topo frio do que com as temperaturas máximas de superfície. Se utilizarmos os dois parâmetros de satélites para calcular uma regressão múltipla e estimar as precipitações, os coeficientes de correlação são bons ( $r>0.61$, ou seja, $50 \%$ da variância explicada) para 7 meses sobre os 12 , mas continuam pouco significativas para 2 meses.

Tabela 1. Coeficientes de correlações ( $r$ ) entre as chuvas medidas em superfície e os dados infravermelhos GOES ; em negrito os coeficientes superiores a 0,60.

\begin{tabular}{|c|c|c|c|c|c|c|c|c|c|}
\hline & & \multirow{2}{*}{ Obs. } & \multicolumn{3}{|c|}{ ocorrências } & \multicolumn{3}{|c|}{ TbMax } & \multirow{2}{*}{$\frac{\text { Occ+TbM }}{\mathrm{R}}$} \\
\hline & & & $r$ & a & $b$ & $r$ & a & $b$ & \\
\hline \multirow[t]{4}{*}{2000} & Setembro & 206 & 0.61 & 6.08 & 14.7 & -0.35 & -5.84 & 270.0 & 0.61 \\
\hline & Outubro & 203 & 0.58 & 4.96 & 3.3 & -0.44 & -6.95 & 325.7 & 0.59 \\
\hline & Novembro & 207 & 0.41 & 5.80 & 66.1 & -0.40 & -12.93 & 546.6 & 0.45 \\
\hline & Dezembro & 206 & 0.41 & 7.03 & 43.0 & -0.48 & -20.94 & 777.4 & 0.58 \\
\hline \multirow[t]{8}{*}{2001} & Janeiro & 201 & 0.52 & 12.68 & -103.0 & -0.67 & -31.62 & 1032.7 & 0.69 \\
\hline & Fevereiro & 200 & 0.31 & 6.49 & 64.3 & -0.66 & -29.78 & 944.3 & 0.67 \\
\hline & Março & 198 & 0.46 & 7.37 & 65.1 & -0.49 & -23.09 & 798.6 & 0.53 \\
\hline & Abril & 196 & 0.69 & 9.47 & -15.0 & -0.64 & -15.80 & 550.7 & 0.71 \\
\hline & Maio & 193 & 0.66 & 7.40 & 17.9 & -0.39 & -8.12 & 297.9 & 0.66 \\
\hline & Junho & 198 & 0.66 & 7.55 & 4.3 & -0.57 & -7.90 & 238.6 & 0.67 \\
\hline & Julho & 196 & 0.69 & 8.29 & 3.4 & -0.48 & -4.69 & 167.5 & 0.69 \\
\hline & Agosto & 197 & 0.38 & 4.24 & 9.6 & -0.06 & -0.37 & 33.7 & 0.38 \\
\hline \multicolumn{2}{|c|}{ Estação 2000-2001 } & 2401 & 0.78 & 8.22 & 3.7 & -0.62 & -17.25 & 619.3 & 0.81 \\
\hline \multicolumn{2}{|c|}{ Pmm anuais } & 167 & 0.81 & 11.87 & -659.7 & -0.40 & -60.01 & 3729.6 & 0.82 \\
\hline
\end{tabular}

Obs. = Número de observações; $\mathbf{O c c}=$ ocorrências mensais de nuvens de topo frio; $\mathbf{T b M a x}=$ Temperatura máxima radiativa mensal; Occ+TbM = regressão múltipla com ocorrência e TbMax; $\boldsymbol{r}=$ correlação; $\boldsymbol{a}$ e $\boldsymbol{b}=$ coeficientes das linhas de regressão.

Em Mato Grosso, no período de setembro de 1999 a agosto de 2001, confrontando os dados de precipitação em superfície com os dados infravermelhos do satélite GOES, verifica-se que as chuvas são melhor correlecionadas com a ocorrência de nuvens de topo frio do que com as temperaturas máximas. A estimativa das precipitações por satélite é, então, bem adaptada para esta região pouco equipada em estações convencionais mas deve privilegiar o primeiro método, o segundo contribuindo apenas para aumentar significativamente a correlação múltipla $(r=0.82)$. 


\section{Exemplos de utilização dos dados NOAA-AVHRR na França do oeste}

Os satélites americanos de órbita polar NOAA são muito complementares dos precedentes. O programa NOAA (National Oceanic and Atmospheric Administration) começou em 1970, na sequência do programa TIROS, e prossegue atualmente ao ritmo médio de um lançamento de dois em dois anos. Situados sobre órbitas baixas (900 Km de altitude) os satélites NOAA são chamado de órbita polar, efetuando uma volta da Terra em cerca de 100 minutos. A sua órbita é quasepolar, uma ligeira desfasagem do seu percurso ao solo em relação aos meridianos que permite-lhes o sobrevôo de todo o planeta (incluídas as elevadas latitudes, contrariamente ao Météosat) e de observar um mesmo ponto cada dia à mesma hora (heliosincrônico). Estes satélites dispõem de um radiômetro que tem uma resolução espacial de cerca de um quilômetro e efetua medidas em 5 canais que respondem às vàrias necessidades tématicas (D'Souza et al., 1996) :

$1: 0,58$ à 0,68 um, visível (albédo)

2 : 0,72 à 1,1 um, infravermelho próximo (estudo da vegetação)

3 : 3,53 à 3,93 um, infravermelho médio (diferenciação das nuvens e neve/gelo)

4 : 10,3 à 11,3 um, infravermelho térmico (temperaturas de superfície)

5 : 11,5 à 12,5 um, infravermelho térmico (temperaturas de superfície)

Ilustraremos esta parte a partir do exemplo da estimativa das temperaturas do ar e o monitoramento da seca na França do oeste.

\subsection{Estimativa das temperaturas do ar na Bretanha}

O conhecimento local do clima, em um ponto não provido de uma estação meteorológica, é da competência da extrapolação dos valores de uma estação relativamente próxima e colocada num ambiente comparável ou uma interpolação espacial a partir de uma malha de pontos de medidas que cercam o setor de estudo. Assim, vários métodos de interpolação espacial dos dados térmicos foram propostos e ainda são utilizados continuamente. Entre os primeiros trabalhos na França pode-se citar os métodos que utilizam regressões simples entre temperaturas e relevo, método enriquecido seguidamente por vários autores entre os quais o Mapa Climático Detalhado da França (CNRS ER30, 1981). De maneira geral, os fatores topográficos (altitudes, inclinações, exposição) são logicamente privilegiados, e o mapa deve integrar os fatores mais influentes conhecidos. Em setores com relevos menos contrastados, é corrente utilizar métodos de interpolação menos dependentes dos parâmetros ambientais (krigeage). Finalmente, poucos trabalhos consideram a natureza da ocupação do solo que influencia no entanto sobre as trocas de energia. Apresentamos aqui um método estatístico de interpolação das temperaturas máximas do ar na Bretanha que utiliza as imagens NOAA-AVHRR para um dia de 1997 (Dubreuil et al., 2002). O interessante é que na Bretanha, por sua situação de peninsula, os efeitos combinados da distância à costa e a latitude 
podem exprimir-se plenamente (altitudes não atingem nunca 400 metros). Por último, a diversidade da ocupação do solo permite utilizar os dados infravermelhos fornecidos pelos satélites NOAA-AVHRR cuja resolução espacial de $1,1 \mathrm{Km}$ é adaptada à nossa problemática.

Para este estudo foram selecionadas 45 estações da rede automática da Météo-France. Estes dados são considerados como mais confiáveis, pois estes postos são regularmente controlados e geridos diretamente pela MétéoFrance. Para uma região de $27000 \mathrm{~km}^{2}$, dispõe-se em média de um ponto de medida para $600 \mathrm{~km}^{2}$. O dia selecionado corresponde à uma situação anticiclônica, com pressões de superfície elevadas centradas na Europa do Noroeste. Esta situação resulta, sobre o conjunto da França, em um céu claro e um fluxo dominante de setor Leste (vento fraco) que conduzia sobre a Bretanha massas de ar continental seco. As situações anticiclônicas radiativas são mais propícias de modo que os contrastes de temperaturas possam exprimir-se em função dos parâmetros de ambiente. A fraqueza do vento desfavorece a mistura do ar que atenua as diferenças de temperatura. O tipo de tempo retido é, por conseguinte, susceptível de fazer surgir os contrastes térmicos locais.

As medidas de radiação infravermelha realizadas pelos satélites NOAA vão servir para informar as temperaturas das superfícies. O radiômetro AVHRR presente à bordo de NOAA-14 mede nas gamas de comprimentos de ondas compreendidas entre 10,3 e 11,3 $\mu \mathrm{m}$ por um lado e entre 11,5 e 12,5 $\mu \mathrm{m}$ por outro lado (respetivamente bandas 4 e 5 ). É necessário ter em conta os problemas de absorção atmosférica que perturbam o sinal captado pelo satélite. É por esta razão que se trabalha no infravermelho a partir de uma combinação dos canais 4 e 5: a técnica do "split-window" é uma equação linear que liga a temperatura de superfície desconhecida às temperaturas de brilhos medidas pelo captor e permite livrar-se parcialmente do constrangimento atmosférico. Entre as diferentes formulações disponíveis na literatura (Ottlé et Vidal-Madjar, 1992), retivemos o método de Vidal Madjar:

$$
T s=T 4+2,78(T 4-T 5)-1,35
$$

Com T4 e T5, temperaturas de brilhos assinaladas pelos canais 4 e 5 do AVHRR e Ts temperatura da superfície. Os dados do infravermelho NOAAAVHRR devem ser considerados aqui como um dos indicadores "preventivos" da temperatura do ar, as duas temperaturas (do ar e superfície) não podem ser confundidas. Os outros indicadores "geográficos" retidos aqui são a latitude, a longitude, a distancia à costa e a altitude.

Os resultados do quadro $\mathrm{n}^{\circ} 2$ mostram que a causa mais determinante das temperaturas do ar para o dia estudado é a latitude. Não é realmente uma surpresa considerando-se que trata de dias ensolarados e o primeiro fator de aumento da temperatura durante o dia é então o contributo radiativo solar proporcional à latitude. A quinta coluna do quadro 4 mostra a correlação obtida efetuando uma regressão múltipla entre estes quatro parâmetros geográficos e a temperatura do ar ( $\mathrm{Ta}$ ) : o coeficiente é muito significativo e permite afirmar que as temperaturas do ar são em essencialmente função da latitude e a distância à costa. A penúltima coluna do quadro permite observar que a correlação é idêntica entre as temperaturas de superfície (Ts) NOAA e a Ta e entre os parâmetros geográficos e a Ta; intrinsecamente, a temperatura de superfície de satélite é um melhor indicador da temperatura do ar do que cada um dos parâmetros geográficos 
selecionados.

Tabela 2. Correlações entre as temperaturas do ar (Ta) e os parâmetros geográficos e do satélite

\begin{tabular}{lccccccc}
\hline 10-04 & $\begin{array}{c}\text { Altitude } \\
\text { (alt) }\end{array}$ & $\begin{array}{c}\text { Distância } \\
\text { para a } \\
\text { costa (dist) }\end{array}$ & $\begin{array}{c}\text { Longitude } \\
\text { (long) }\end{array}$ & $\begin{array}{c}\text { Latitude } \\
\text { (lat) }\end{array}$ & 4 parâmetros & $\begin{array}{c}\text { Satélite } \\
\text { (Ts) }\end{array}$ & $\begin{array}{c}\text { Todos os } \\
\text { fatores }\end{array}$ \\
\hline Correlação & 0.26 & 0.58 & 0.36 & -0.68 & 0.81 & 0.81 & 0.92 \\
\hline
\end{tabular}

A fim de propôr uma fórmula de interpolação das temperaturas do ar, uma regressão linear múltipla foi realizada. É então possível exprimir a temperatura do ar como o produto de uma combinação linear de várias variáveis. A fórmula obtida para o dia de 10 de Abril de 1997 é a seguinte :

$T a(10 a b r i l)=80.75+0.27 T s+0.0028 a l t+0.0303$ dist $-0.0282 l a t-0.0024 l o n g$

Calculando o desvio entre a temperatura considerada pelo modelo e a temperatura realmente medida nas 45 estações estudadas, os desvios superiores à $2^{\circ}$ representam menos de um caso em $10(9,6 \%)$ e em quase 2 de cada 3 casos (entre 62 e 71\%) o erro de estimativa pelo modelo é inferior à $1^{\circ}$. O estudo dos resíduos em relação à este modelo mostra que trata-se para a maior parte dos casos de estações litorais: o modelo parece melhor reproduzir as variações espaciais das temperaturas ao interior do continente, sem dúvida devido a grande heterogeneidade dos pixéis NOAA em região de contacto terra/mar. Finalmente é possível construir um mapa de temperaturas do ar a partir da fórmula de regressão múltipla. Obtém-se assim um mapa (ou mais exatamente uma nova imagem a um quilômetro de resolução espacial!) onde o valor da temperatura do ar de cada ponto é em função das suas características geográficas e a temperatura de superfície medida pelo NOAA (figura 5).

\subsection{Monitoramento da seca na Bretanha por índice de vegetação NDVI}

A seca estival é um constrangimento essencial em climatologia: afetando os recursos de água, torna problemático o crescimento da cobertura vegetal. Em regiões onde a agricultura é importante, pode ter repercussões sérias sobre o conjunto da economia. Para efetuar um acompanhamento da maneira como a cobertura vegetal é afetada pelo déficit de água pode-se utilizar os dados fornecidos pelos satélites NOAA ou SPOT-Vegetação e sobretudo as imagens do infravermelho próximo. Neste canal, com efeito, a reflectância dos vegetais é em função da estrutura de suas células, fortemente dependente do seu teor de água. Calculando um índice de vegetação (combinação de informações procedentes de diferentes bandas espectrais) à datas diferentes pode-se então comparar o estado da cobertura vegetal em diferentes momentos do ano. Entre os índices de vegetação mais correntemente utilizados, o NDVI (Normalized Difference Vegetation Index ; Rouse et al., 1974) permite efetivamente destacar a vegetação clorofílica utilizando as bandas vermelha e infravermelho próximo (IVP) dos captores: 


$$
N D V I=\frac{I V P-\text { Vermelho }}{I V P+\text { Vermelho }}
$$

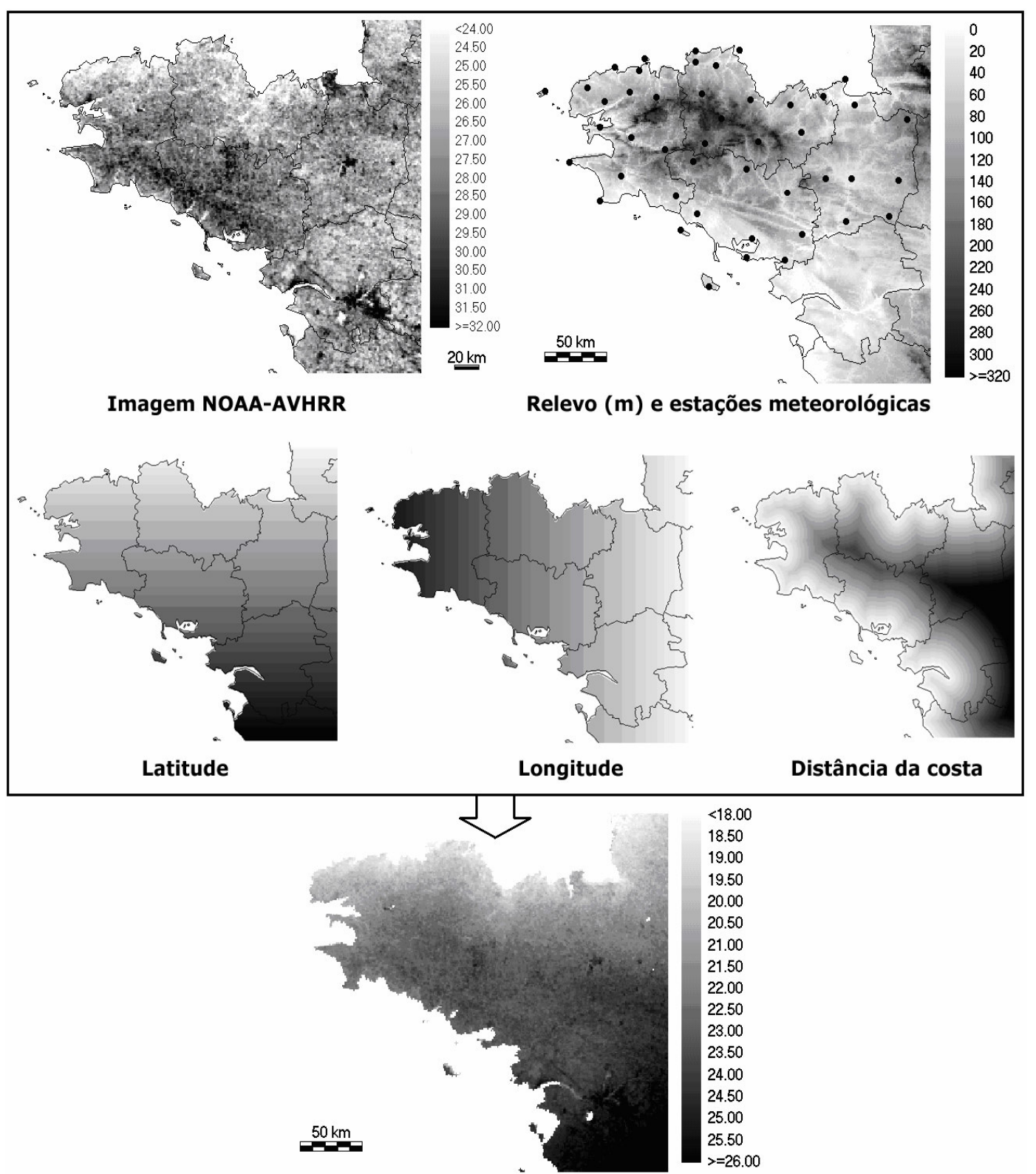

Figura 5. Estimativa das temperaturas máximas do ar o 10 de Abril de 1997 na Bretanha a partir dos parâmetros geográficos e dos dados NOAA-AVHRR

Para livrar-se da cobertura de nuvens e dos problemas ligados à absorção pela atmosfera (Bariou et al, 1987), sínteses de imagens são constituídas a partir do método do "MVC" (Maximum Value Composite) em geral calculadas sobre 10 dias ou um mês. O MVC tem por efeito reduzir as diferenças de ângulo solar, minimizar a presença das nuvens e dos efeitos da 
atmosfera devidos à presença de aerossol e de vapor de água (Holben, 1986). As sínteses de MVC NDVI são atualmente utilizadas para a análise da cobertura vegetal na escala global ou continental. Contudo, se os MVC NDVI minimizam certos efeitos que perturbam os valores radiométricos dos pixéis, não o suprimem totalmente das imagens.

Contudo, a interpretação das imagens NOAA é complexa devido à resolução espacial do captor AVHRR (um quilômetro ao nadir). De maneira geral, o acompanhamento da cobertura vegetal com o índice de vegetação NDVI não é fácil. Com efeito, este índice pode ser fraco devido à uma ausência perfeitamente normal de vegetação (colmos ou labours), ou devido a fase de desenvolvimento atingida (senescencia), ou devido um déficit de alimentação de água das plantas que se reflete sobre o seu teor de clorofila. O bom conhecimento do dossel, sobre o terreno, é por conseguinte indispensável e deve permitir distinguir estas duas possibilidades. Isto significa que uma imagem de NDVI não pode ser considerada em si como um mapa de seca como este pode ser um mapa dos déficites hídricos. Em contrapartida, o estudo combinado de imagens tomadas sobre um ano não deficitário (ou sobre uma média de vários anos) e confrontadas às cartografias das deficiências de evaporação dá uma extensão espacial muito detalhada das regiões anomalamente deficitárias. É à este nível que reside o interesse das imagens dos satélites à baixa resolução espacial: permitir uma abordagem comparativa da extensão espacial fina do estado da cobertura vegetal por aproximação com os mapas de déficites correspondentes.

Durante o verão 2003, as temperaturas elevadas bem como a falta de água resultaram na limitação do desenvolvimento dos vegetais. As séries temporais de NDVI NOAA AVHRR mostram um forte decrescimento do NDVI e, por conseguinte, das taxas de cobertura vegetal sobre as superfícies agrícolas a partir de junho 2003, uma baixa que nos anos precedentes ocorria apenas em Setembro e não era tão marcada. (figura 6).

\section{NDVI}

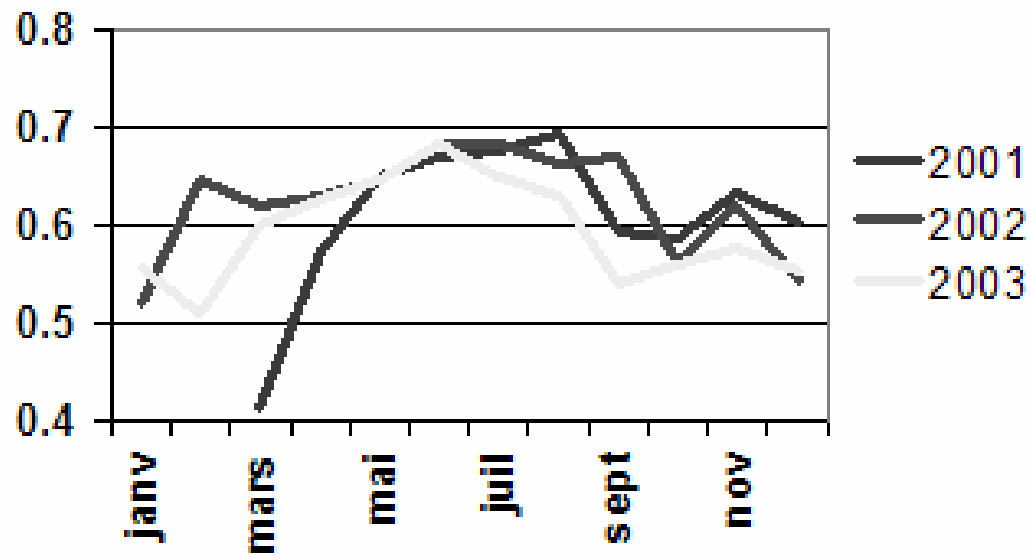

Figura 6. Comparação dos perfis anuais de NDVI NOAA-AVHRR sobre as superfícies à dominante forrageiras 
É necessário, por conseguinte, relacionar o NDVI e o déficit de evaporação para uma abordagem fina da seca à escala regional. Os mapas da figura 6 mostram, para cada um dos 4 meses do verão 2003, o estado do défice de evaporação (calculado aqui com o ETP Turc e uma reserva útil de $125 \mathrm{~mm}$ ) e o índice de vegetação mensal obtido a partir dos dados NOAAAVHRR (figura 7). Sobre estas imagens pode-se opôr a Bretanha ocidental, cujos índices de déficites continuam a ser fracos e índices de vegetação elevados, e a Bretanha oriental onde a seca foi mais intensa (sobretudo em agosto) e os índices de vegetação claramente mais baixos. Pode-se igualmente observar que o déficit importante observado em agosto (e que se prolonga ao leste em setembro) reflete-se realmente apenas sobre os valores de NDVI de setembro: essa defasagem de um mês entre os 2 mapas é devido ao mesmo tempo a reação da vegetação ao stress climático e ao modo de aquisição dos dados de teledetecção (MVC revistas mensais).

Região reconhecidamente como úmida, a Bretanha conhece por conseguinte às vezes situações de déficites prolongados e pronunciados que, certos anos, afetam de maneira mais ou menos grave a produção agrícola. A espacialização detalhada de um fenômeno também complexo e difuso como a seca necessita de utilizar os dados de teledetecção. A concordância dos resultados fornecidos pelos métodos de balanço hídrico e acompanhamento do NDVI incita a pensar que uma correlação oposta existe entre o valor do NDVI e da deficiência de evaporação. Em teoria, uma deficiência de evaporação elevada corresponderia à fracos valores do NDVI, tradutora dos fenômenos de seca. Mas, se o valor do D.E. tem um significado local concreto, a interpretação dos NDVI é mais delicada. É necessário, com efeito, ter em conta as práticas agrícolas e os tipos de cobertura para propor uma análise realista das variações do sinal do satélite escolhido.

A escolha dos dados NDVI à baixa resolução NOAA-AVHRR parece particularmente bem adaptada para um estudo regional mas é conveniente dar os limites da análise aqui proposta:

- a resolução espacial quilométrica não permite distinguir o impacto da seca num tipo de ocupação do solo em especial. A análise, por conseguinte, foi efetuada sobre misturas de diferentes culturas. Não é possível precisar os tipos de cobertura que foram impactados pela falta de água;

- a isto acrescenta-se as defasagens temporais devidos aos métodos de pré-tratamento das imagens. As sínteses mensais de NDVI vão conservar valores de índices adquiridos no início dos meses apesar da baixa que ocorreu durante o conjunto do período de aquisição das imagens. Falta precisão do ponto de vista espacial e temporal na análise e a utilização de imagens diárias à média resolução (do tipo dos dados MODIS) pode ser importante para limitar estes efeitos de defasagens temporais e mistura dos pixéis. 


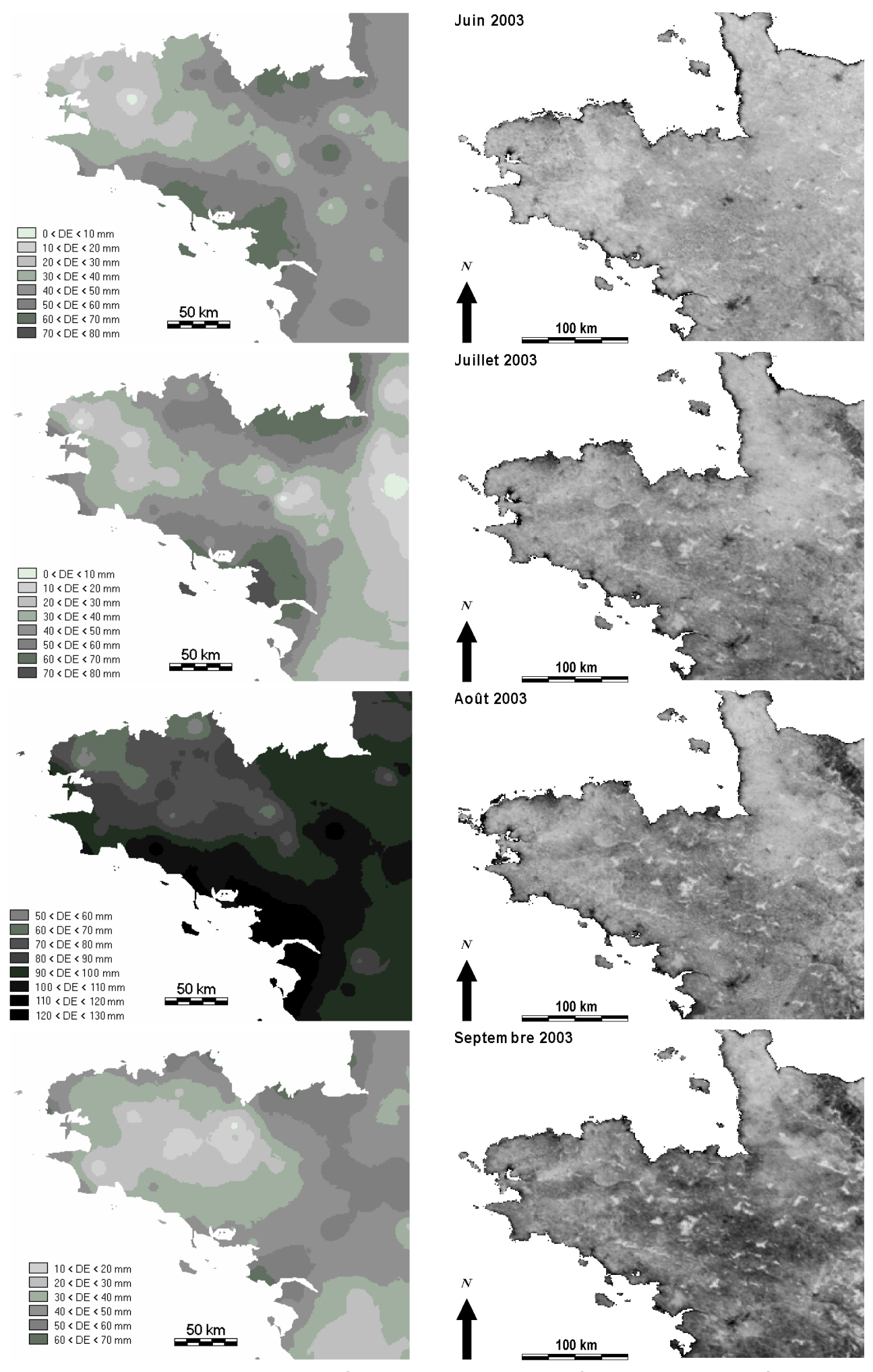

Figura 7. Monitoramento do déficit de evaporação (à esquerda) e o índice de vegetação NDVI (à direita) durante o verão 2003 em Bretanha 


\section{Conclusão}

No conjunto, o geógrafo-climatólogo dispõe de uma quantidade impressionante de informações diversificadas e complementares. A nossa atmosfera é supervisionada permanentemente e em vários níveis e meios consideráveis são implantados nesta perspectiva. Com efeito, quanto maior o nosso conhecimento da atmosfera, melhor será a previsão meteorológica fornecida pelos modelos. Além disso, o bom conhecimento dos elementos do clima permite certa adaptação das atividades econômicas, das construções... e de suas roupas ! Neste sentido, o clima está no coração das preocupações diárias dos indivíduos e da sociedades e contribui fortemente para caracterizar o meio geográfico.

\section{ReferênciasBibliográficas}

ARKIN P.A., JANOWIAK J.E., 1993 : Tropical and Subtropical precipitation, in « Atlas of satellite observations related to global change» Ed.by R.J.Gurney, J.L.Foster, C.L.Parkinson; Cambridge University Press, pp.165-180

BADER J.M., FORBES G.S., GRANT J.R., LILLEY R.B.E., WATERS A.J., 1995: Images in weather forecasting : a practical guide for interpreting satellite and radar imagery, Cambridge University Press, 499p.

BARIOU R., LECAMUS D., LE HENAFF F., 1987: Corrections atmosphériques, Dossiers de télédétection $\mathrm{n}^{\circ} 7, \mathrm{COSTEL}$ - Presses Universitaires de Rennes, $116 \mathrm{p}$.

BARRETT E.C., 1974: Climatology from satellites, Methuen \& Co ; 418p.

CADET D., GUILLOT B., 1991: EPSAT: Estimation des Pluies par Satellite; ORSTOM, 63p.

BURROUGHS W.J., 1991: Watching the world's weather, Cambridge University Press

CNRS-ER30, 1980: Carte Climatique détaillée de la France au 1/250.000, Feuilles de Brest, Saint-Brieuc Lorient, Nantes, Rennes; Ed. Ophrys, Paris-Gap

D'SOUZA G., BELWARD A.S., MALINGREAU J.P., 1996: Advances in the use of NOAAAVHRR data for land applications, Kluwer Academic Publishers, 479p.

DAMATO, F., PLANCHON, O. et DUBREUIL, V. (2003) A remote sensing study of the inland penetration of sea breeze fronts from the English Channel, Weather, 58 (6), 219-225.

DUBREUIL V., BARIOU R., DOS PASSOS M.M., MAITELLI G.T., 2002: Environnement et télédétection au Brésil, Presses Universitaires de Rennes, 200p.

DUBREUIL V., MARCHAND J.P., 1997: Le climat, l'eau et les hommes, Presses Universitaires de Rennes, 333p.

DUBREUIL V., MONTGOBERT M., PLANCHON O., 2002 : Une méthode d'interpolation des températures de l'air en Bretagne : combinaison des paramètres géographiques et des mesures infrarouge NOAA-AVHRR ; Hommes et Terres du Nord ; 2002-1 ; pp.2639

DUBREUIL V., JALLET A., RONCHAIL J., MAITELLI G., 2004 : Estimation des précipitations par télédétection au Mato Grosso (Brésil) ; Annales de I'AIC, Volume 1, pp.133-156

GUILLOT B., DAGORNE D., PENNARUN J., LAHUEC J.P., 1994: Satellite et surveillance du climat; Atlas de veille climatique: 1986-1994, ORSTOM Editions, 91p.

GURNEY R.J., FOSTER J.L., PARKINSON C.L., 1993: Atlas of satellite observations related to global change, Cambridge University Press, 470p.

HOLBEN B. N., 1986, Characteristics of maximum-value composite images from temporal AVHRR data, International Journal of Remote Sensing, 7 (11), pp.14171434. 
KERGOMARD C., 2004 : Réflexions sur trente années d'usage de la télédétection satellitale en climatologie ; Actes du XVIIe Colloque de I'Association Internationale de Climatologie, Caen, pp.55-58

LE ROY LADURIE E., 1983 : Histoire du climat depuis I'an Mil ; Coll. Champs, Flammarion; Paris; 2 tomes, 287 et 254p.

LOMBARDO, M.A. 1989 : A ilha de calor nas metrópoles: O caso de São Paulo. São Paulo: Hucitec

MENDONÇA, F.A., 1995 : O clima e o planejamento urbano de cidades de porte médio e pequeno: Proposição metodológica e sua aplicação à cidade de Londrina/PR. São Paulo: USP, Tese de Doutorado.

MOUNIER J., LOZAC'H M., 1981 : L'étude de la nébulosité au-dessus de la France à partir des photos de satellites. Eaux et climats, Mélanges à C.P.Péguy, Grenoble, pp.353-368

MOUNIER J., PAGNEY P., 1982: Climats et satellites. Annales de géographie, n505, $1982 ;$ pp.275-299

MOUNIER J. (dir.), 1990 : Climatologie et télédétection ; Publications de l'Association Internationale de Climatologie ; vol.3, 443p.

NIMER E., 1989 : Climatologia do Brasil, IBGE, Rio de Janeiro, 421p.

OTTLÉ C., VIDAL-MADJAR D., 1992 : Estimation of land surface temperature with NOAA9 data, Remote Sensing of Environment, 40, pp.27-41

PAILLEUX J., 2002 : Les besoins en observations pour la prévision numérique du temps, La Météorologie, n³9, pp.29-35

PEGUY C.P., 1989: Jeux et enjeux du climat. Masson, Paris; 254p.

RAINER J.M., 2003 : Les satellites météorologiques. La Météorologie n40, pp.28-32

ROCHAS M., JAVELLE J.P., 1993 : La Météorologie, Syros

ROUSE J. W., HAAS R. H., DEERING D. W., SCHELL J. A. ET HARLAN J. C., 1974, Monitoring the vernal advancement and retrogradation (green wave effect) of natural vegetation. Greenbelt, Maryland, NASA/GSFC: 371p.

SCHIFFER R.A., ROSSOW W.B., 1983 : The International Satellite Cloud Climatology Program (ISCCP) : the first project of the World Climate Research Program. Bull. Amer. Meteor. Soc., 64, pp.779-784

TABEAUD M., 1989 : L'Atlantique tropical austral : l'eau atmosphérique et le climat en milieu océanique. Thèse de Doctorat de I'Université Paris IV, 439p.

TONNERRE-GUERIN M.A., 1976: A propos de quelques techniques d'utilisation des images satellites en météorologie: contribution à l'analyse synoptique des latitudes moyennes de l'hémisphère nord. Norois, n89, pp. 5-31

WAHL L., 1997 : La dynamique spatio-temporelle des brouillards de rayonnement dans le Fossé Rhénan méridional à l'aide d'images NOAA-AVHRR. Thèse de Doctorat de Géographie de I'Université de Strasbourg.

\section{Agradecimentos}

O autor agradece Dominique Dagorne (IRD, Lannion), Hervé Roquet e Jean-Pierre Olry (SATMOS, Lannion) pela aquisição e pré-tratamento das imagens ; Anne Jallet, Aline Lecamus, Virginie Jumeau, Frédéric Damato, Olivier Planchon, Rémi Lecerf e Pascal Gouery (COSTEL, Rennes 2) ; Neli de Mello pela ajuda na tradução; também a Josyane Ronchail, Andrelina dos Santos e Waldemar Guimaraes (ANA-SIH, Superintendência de Informações Hidrológicas)e Meteo-France pelo acesso aos dados climáticos. 